(RESEARCH ARTICLE)

\title{
Research Output from IISc during 1999-2020: Scientometrics Analysis Case Study
}

\author{
Nagarjuna Pitty * \\ Senior Scientific Officer, JRDTML, IISC, Bengaluru, India.
}

Publication history: Received on 16 November 2020; revised on 10 December 2020; accepted on 12 December 2020

Article DOI: https://doi.org/10.30574/wjaets.2020.1.2.0025

\begin{abstract}
Over the past Seven decades the knowledge or web of science database maintaining the core collections of Science Citation Index Expanded, and past Conference Proceedings Citation Index-Science and past two decades SciELO Citation Index, Journal citation reports. This paper analyses a results of a scientometric analytical case study of the research activities of highly cited papers from 1999 to 2020. This paper study a growth of publications, citations, average citations per publication and H- index of top scientists or researchers, at Indian Institute of Science, Bengaluru, India. Besides that, this paper presents a citation-based mapping of data on global scientific activities from Indian Institute of Science, Bengaluru, India research publications using Web of Science Database. Using different kind of scientometric approaches, such as a h-index and Global Citation Scores. Researchers have published 32191 publications during 19992020 and cited at least 5519 times by end of 2020 are analyzed. Authors have been able to place their papers in high impact journals such as Physics, Engineering, Chemistry, Materials Science, Science \& Technology, Computer Science, Biochemistry Molecular Biology, Mechanics, Mathematics, Telecommunications, and Crystallography. The study discloses an output of Indian Institute of Science Research Publications has greatly increased over period.
\end{abstract}

Keywords: Web of Science; Scientometrics; Citation Map; Indian Institute of Science; Global Citation Scores

\section{Introduction}

In the area of library and information science scientometrics is a branch. Scientometrics tools shall be used to measure and compare the scientific activities at various levels including distribution of publications such as year wise, document type-wise, subject wise, source/journal wise, countries-wise, authors wise and highly cited papers with citation map. It is concerned with a characteristics of science and scientific research and quantitative features.

\subsection{About Indian institute of science}

Indian Institute of Science, Bengaluru, is a forefront of research and education in a basic science subjects and engineering technology subjects. Today, Institute has a very high international reputation in the academic world, in view of the fact; it has expertise both in conventional and emerging areas of science and engineering. It also offers post graduate research and course work. The Institute has more than 45 departments and centers staffed by high caliber scientists. The Institute offers an opportunity for young researchers to pursue doctoral and post-doctoral studies in science subjects and engineering subjects. The institute also offers undergraduate program by providing an opportunity for young scientist.

\subsection{Objectives of the study:}

- To analyze the yearly growth of publications and it related citations.

- To analyze the document type-wise distribution of publications.

- To know the top subject-wise publications.

\footnotetext{
${ }^{*}$ Corresponding author: Mr. Nagarjuna, Pitty

Senior Scientific Officer, JRDTML, IISc, Bengaluru, India. nagarjun@iisc.ac.in.
} 
- To know the top country-wise publications.

- To know the top source/journal-wise publications.

- To identify the prolific authors wise distributions of Publications.

- To identify the highly cited papers with Citation Map from Indian Institute of Science, Bangalore

\section{Material and methods}

From Web of Science database the data collected for the period 1999-2020. It can be seen that nearly 32191 bibliographic records of contribution by Indian Institute of Science Bengaluru, India researchers over the period of 22 years. The researcher applied a search strings "Indian Inst Sci" that has used for related information abstraction from the database of Science Citation Index total 21 years to download related data. A total of 32191 records are downloaded by using Web of Science inbuilt software applications as per the objectives of the study. Further based on citation per paper with number of high quality papers are also applied to find out the quality. The study aims to analyze the thrust areas of research concentration.

\section{Results and discussion}

\subsection{Analysis and Interpretations yearly growth of publications and it related citations}

Table 1 shows that in the period of 22 years (1999-2020) a total of 32191 publications were published at Global level. The huge publication is 2239 in 2014 followed by 2160 papers in 2015 and 2086 papers in 2016. The lowest number 162 in the year 2020. In my study reveals all these 519184 publications have Total Global Citation Score it shows that there is a maximum no of citation are published among the scientists from Indian Institute of Science, Bengaluru.

Table 1 Yearly growth of Publications and its related citations.

\begin{tabular}{|l|l|l|l|l|l|}
\hline Years & $\begin{array}{l}\text { Total Publications } \\
\text { (TP) }\end{array}$ & Percentage & $\begin{array}{l}\text { Total Citations } \\
\text { (TC) }\end{array}$ & $\begin{array}{l}\text { Average Citation Per } \\
\text { Publications (ACP) }\end{array}$ & H-Index \\
\hline 1999 & 852 & 2.66 & 27372 & 32.12 & 64 \\
\hline 2000 & 943 & 2.94 & 26797 & 28.41 & 76 \\
\hline 2001 & 992 & 3.09 & 27275 & 27.49 & 74 \\
\hline 2002 & 1064 & 3.32 & 25080 & 23.57 & 70 \\
\hline 2003 & 1190 & 3.71 & 27648 & 23.23 & 72 \\
\hline 2004 & 1191 & 3.71 & 29239 & 24.54 & 74 \\
\hline 2005 & 1310 & 4.09 & 29935 & 22.85 & 74 \\
\hline 2006 & 1430 & 4.46 & 29243 & 20.44 & 74 \\
\hline 2007 & 1507 & 4.70 & 31409 & 20.84 & 71 \\
\hline 2008 & 1554 & 4.85 & 34998 & 22.52 & 81 \\
\hline 2009 & 1699 & 5.30 & 39165 & 23.05 & 81 \\
\hline 2010 & 1657 & 5.17 & 31612 & 19.07 & 70 \\
\hline 2011 & 1668 & 5.20 & 31520 & 18.89 & 68 \\
\hline 2012 & 1861 & 5.81 & 27631 & 14.84 & 60 \\
\hline 2013 & 2007 & 6.25 & 29264 & 14.58 & 63 \\
\hline 2014 & 2239 & 6.99 & 24362 & 10.88 & 54 \\
\hline 2015 & 2160 & 6.74 & 19656 & 9.1 & 48 \\
\hline 2016 & 2086 & 6.51 & 14653 & 7.02 & 37 \\
\hline 2017 & 2062 & 6.43 & 8886 & 4.30 & 31 \\
\hline 2018 & 2045 & 6.38 & 3345 & 1.63 & 16 \\
\hline 2019 & 512 & 1.59 & 89 & 0.17 & 3 \\
\hline 2020 & 162 & 0.03 & 5 & 0.03 & 1 \\
\hline Total & 32,191 & 100.00 & $5,19,184$ & 365.57 & 1,262 \\
\hline & & Source: Web of Science February 2020 & & \\
\hline
\end{tabular}




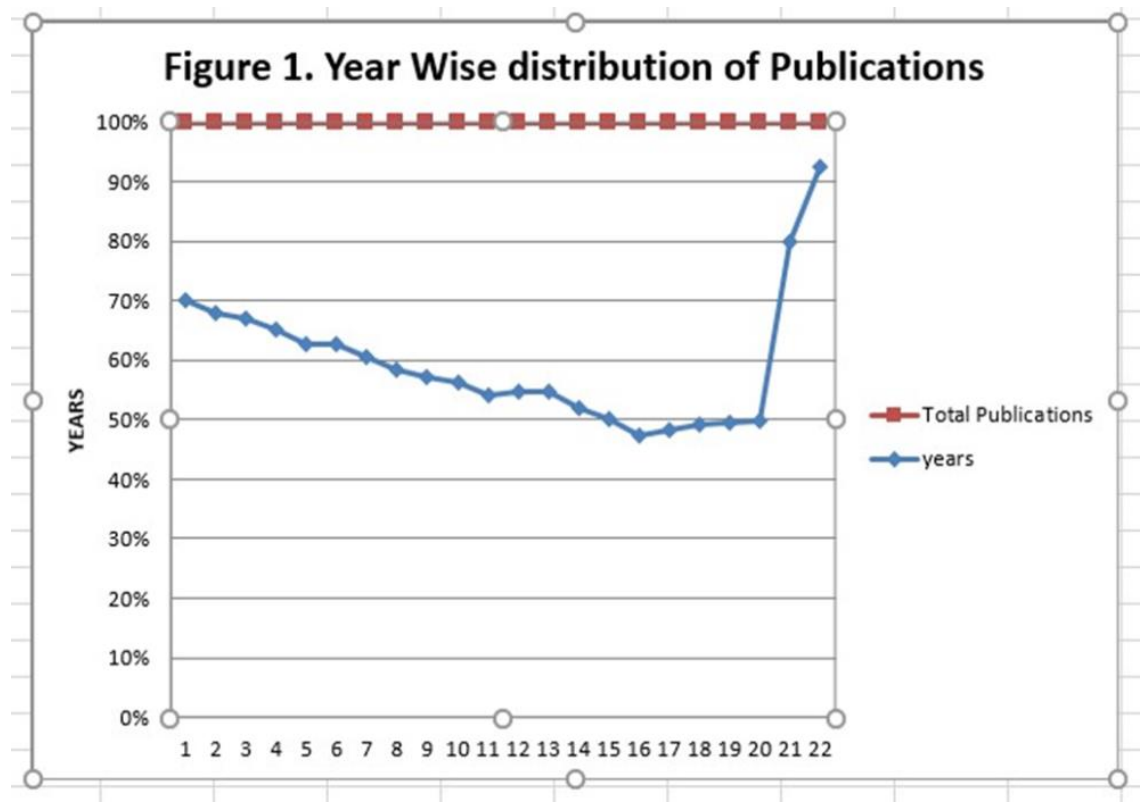

Figure 1 Yearly growth of publications and its related citations and highest publication is 2239 in the year 2014 and lowest publication is 162 in the year 2020

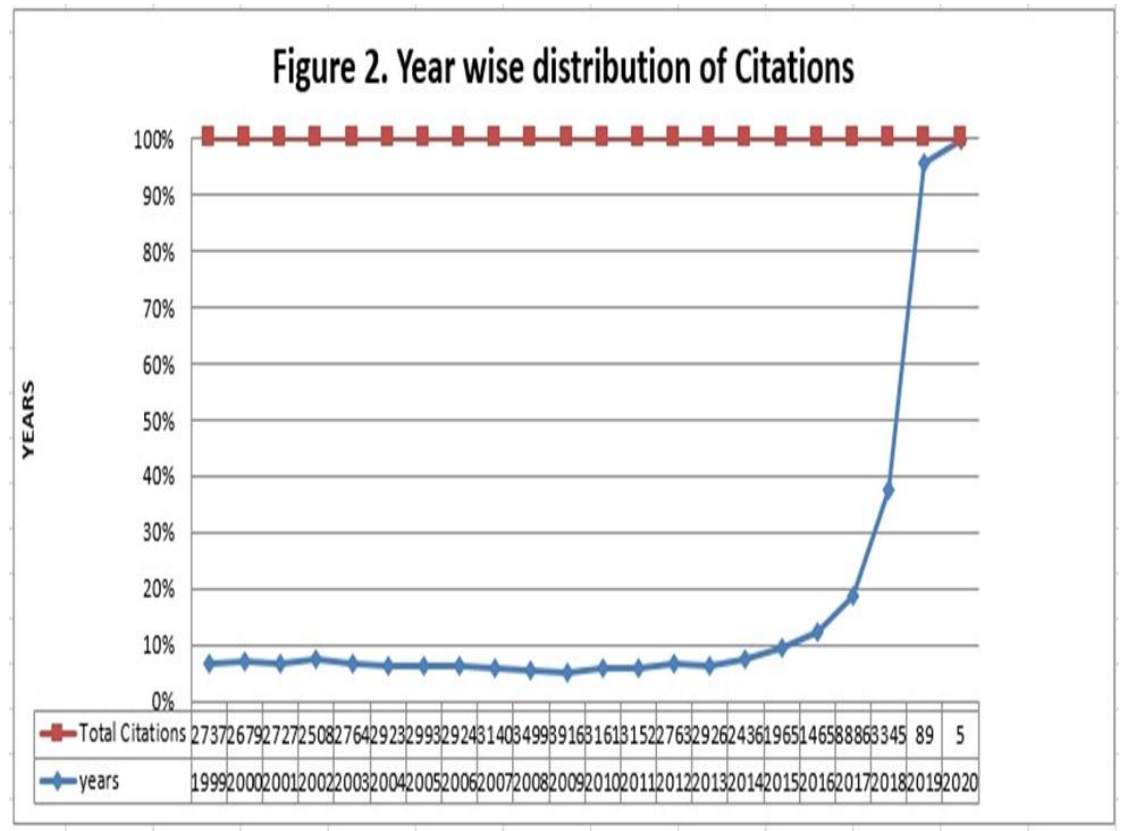

Figure 2 Shows the highest Citations is 39165 in the year 2009 and lowest citations is 5 in the year 2020

\subsection{Document wise Distribution of Publications}

The table 2 depicts the top 10 document wise distribution of articles published in the journal during 1999 to 2020 . The productivity of scientists spreads over variety of publication media, such that journal articles; article, proceedings paper; Meeting abstract, review; letter; editorial materials; correction; meeting abstracts; article, book chapters; correction, Item about an individual and other news items. Table-2 analysis that the share of Articles is the most prominent bibliographic publications and it occupies 25666 (77.15\%). Proceedings Paper has 5603 (13.71\%) contributions, Review papers has 705 (1.99\%) contributions, Editorial materials has 508 (1.47\%), Meeting abstract has $344(1.01 \%)$ and followed by remaining Letter, Correction, Bibliographic Item. Remaining document types like Book Chapter, News item are scored the lowest total number $31(0.09 \%)$ of publications for communication among the scientists. 
Table 2 Document Wise Distributions of Publications

\begin{tabular}{|l|l|l|}
\hline Document Types & TP & Percentage \\
\hline Article & 25666 & 77.15 \\
\hline Proceedings Paper & 5603 & 13.71 \\
\hline Review & 705 & 1.99 \\
\hline Editorial Material & 508 & 1.47 \\
\hline Meeting Abstract & 344 & 1.01 \\
\hline Letter & 198 & 0.58 \\
\hline Correction & 124 & 0.37 \\
\hline Biographical Item & 51 & 0.15 \\
\hline Book Chapter & 35 & 0.10 \\
\hline News Item & 31 & 0.09 \\
\hline
\end{tabular}

Source: Web of Science February 2020

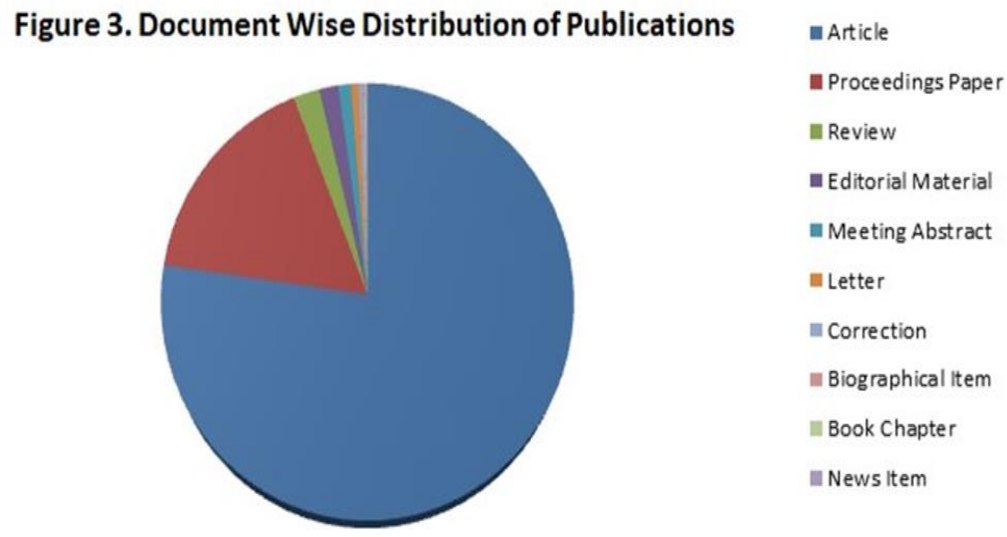

Figure 3 Shows journal articles is top ranked with 25666 (77.15\%) and News item is lowest rank with $31(0.09 \%)$

\subsection{Subject Wise Distributions of publications}

The table 3 depicts the top 10 subject-wise distribution of articles published in the journal during 1999 to 2020 Materials Science Multidisciplinary subject is top ranked with 5051 (21.03\%) publications, followed by Engineering Electrical Electronic subjects with 3813 (8.09\%) publications, while Physics Applied subject ranked third with 3009 $(14.74 \%)$ publications and followed by remaining subjects.

Table 3 Subject Wise Distributions of Publications

\begin{tabular}{|l|l|l|l|l|l|l|}
\hline Sl. No. & Subjects & TP & Percentage & TC & ACP & H-Index \\
\hline 1 & Materials Science Multidisciplinary & 5051 & 21.03 & 106212 & 21.02 & 116 \\
\hline 2 & Engineering Electrical Electronic & 3813 & 8.09 & 30830 & 8.08 & 68 \\
\hline 3 & Physics Applied & 3009 & 14.74 & 44364 & 14.74 & 80 \\
\hline 4 & Chemistry Physical & 2775 & 26.49 & 73496 & 26.48 & 111 \\
\hline 5 & Chemistry Multidisciplinary & 2216 & 28.89 & 64017 & 28.88 & 101 \\
\hline 6 & Physics Condensed Matter & 2016 & 17.86 & 36012 & 17.86 & 77 \\
\hline 7 & Biochemistry Molecular Biology & 1990 & 19.34 & 38479 & 19.33 & 72 \\
\hline 8 & Multidisciplinary Sciences & 1435 & 17.83 & 25580 & 17.82 & 64 \\
\hline 9 & Nanoscience Nanotechnology & 1353 & 23.21 & 31400 & 23.20 & 73 \\
\hline 10 & Telecommunications & 1271 & 4.64 & 5894 & 4.63 & 35 \\
\hline
\end{tabular}

Source: Web of Science February 2020 
Remaining document types like Chemistry Physical, Chemistry Multidisciplinary, Physics Condensed Matter, Biochemistry Molecular Biology, Multidisciplinary Sciences, Nanoscience Nanotechnology and Telecommunications are lowest numbers 1271 (4.64), 1353 (23.21), 1990 (19.34), 2016 (17.86) and 1435 (17.83\%) respectively for subject wise distributions of publications.

Figure-4 Shows subject physics is top rank with 4285 (19.01\%) and Subject Crystallography is lowest rank with 733 $(3.25 \%)$.

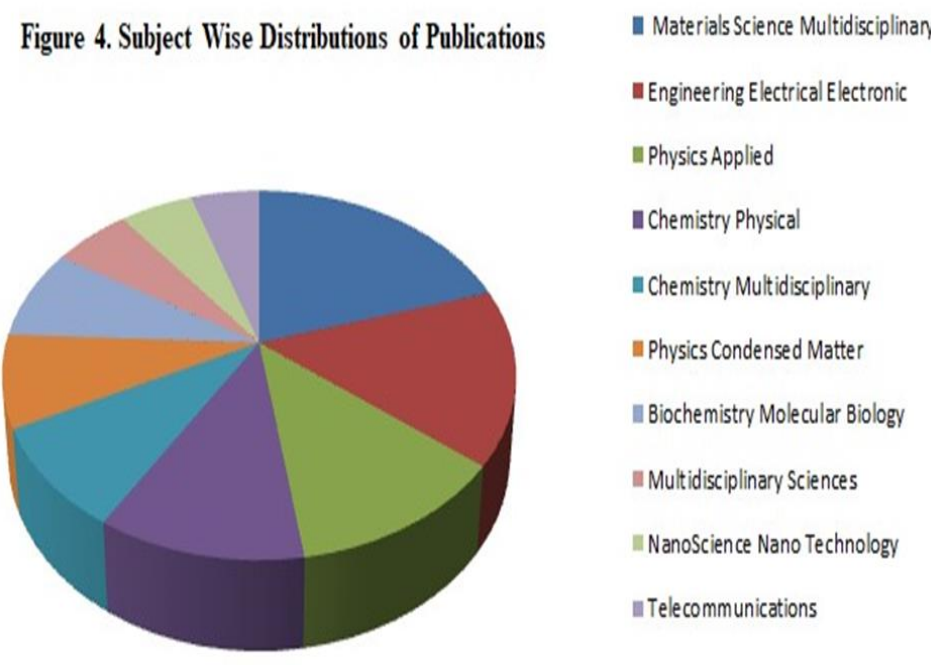

Figure 4 Shows subject Materials Science Multidisciplinary is top rank with 5051 (21.03\%) and Subject Telecommunications is lowest rank with 1271 (4.64\%).

\subsection{Top country-wise Distribution of Publication}

The table 4 depicts the top 10 country-wise distribution of articles published in the journal during 1999 to 2020 from Indian Institute Science scientists/authors. India is top ranked with 32032 (NA \%) publications, followed by USA with 3398 (25.42\%) publications, while France ranked third with 1177 (21.86\%) publications and followed by England, Japan etc. Remaining country wise distribution of publications like South Korea, Italy Japan, Peoples R China and Australia are lowest numbers 453 (18.22\%),490 (20.71\%), 534 (24.47\%), 544 (17.15\%), and 548 (36.98\%) respectively.

Table 4 Country Wise Distribution of Publications

\begin{tabular}{|l|l|l|l|l|l|l|}
\hline Sl. No. & Counties & TP & Percentage & TC & ACP & H-Index \\
\hline 1 & India & 32032 & NA & NA & NA & NA \\
\hline 2 & USA & 3398 & 25.42 & 86393 & 25.42 & 116 \\
\hline 3 & France & 1177 & 21.86 & 25725 & 21.85 & 70 \\
\hline 4 & Germany & 1145 & 19.77 & 22633 & 19.76 & 63 \\
\hline 5 & England & 948 & 25.19 & 23884 & 25.19 & 65 \\
\hline 6 & Japan & 548 & 36.98 & 20266 & 36.98 & 63 \\
\hline 7 & South Korea & 544 & 17.15 & 9332 & 17.15 & 42 \\
\hline 8 & Italy & 534 & 24.47 & 13068 & 24.47 & 52 \\
\hline 9 & Peoples R China & 490 & 20.71 & 10148 & 20.71 & 45 \\
\hline 10 & Australia & 453 & 18.22 & 8255 & 18.22 & 39 \\
\hline
\end{tabular}




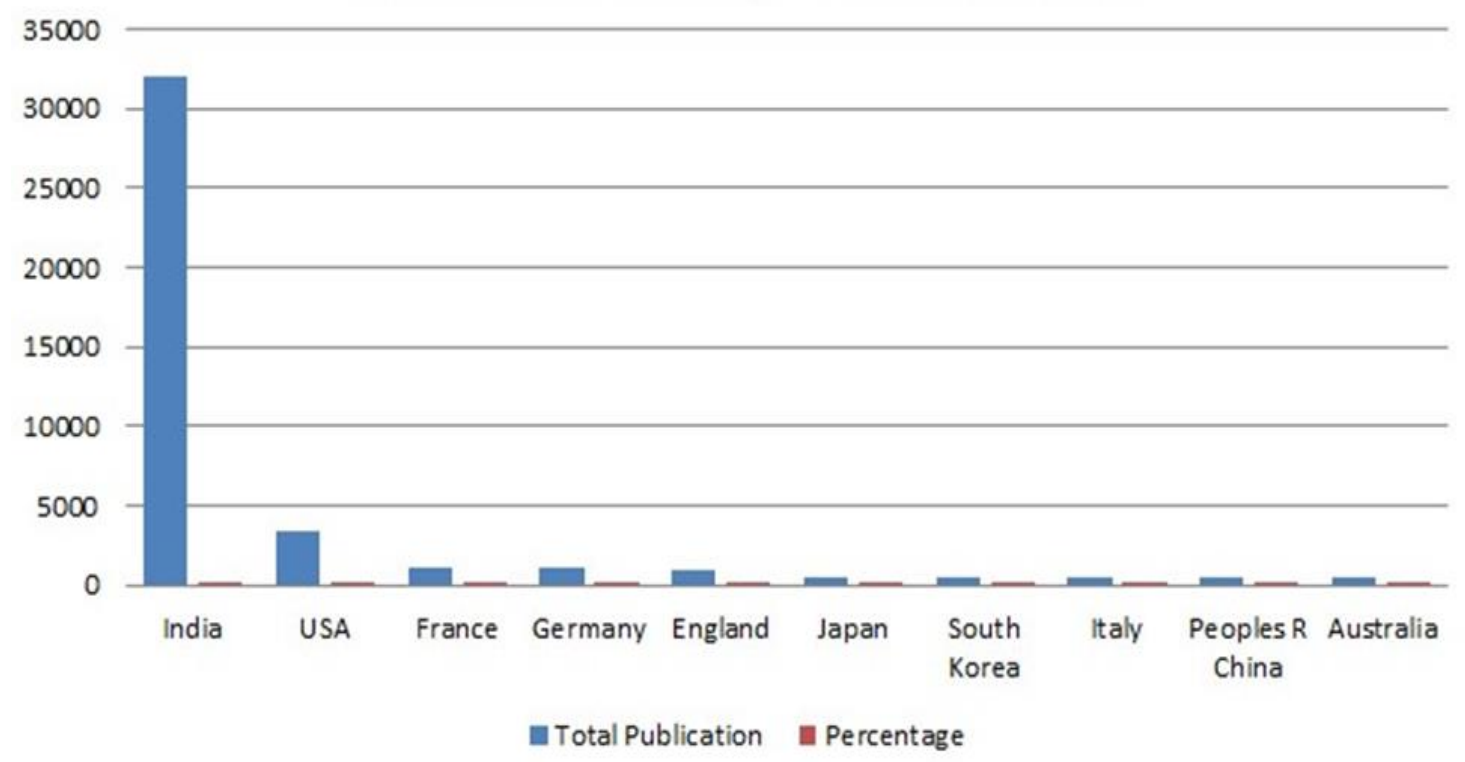

Figure 5 Shows country wise India is top rank with $3032(\mathrm{Na} \%)$ and Australia is lowest rank with $453(18.22 \%)$

\subsection{Source Wise Distribution of Publications}

The table 5 depicts the source wise distribution of publications published in the journal during 1999 to 2020 from IISc scientists/authors. Current Science is top ranked with 683 (8.57\%) publications, followed by Physical Review B with $468(26.75 \%)$ publications, Journal of Chemical Physics ranked third with 309 (16.67\%) publications and followed by other Journal titles. Remaining source wise distribution of publications like Lecture Notes in Computer Science, Journal of Physical Chemistry B, Applied Physics Letters and Physical Review Letters are low numbers of publications i.e. below on percentage.

Table 5 Source Wise Distribution of Publications

\begin{tabular}{|l|l|l|l|l|l|l|}
\hline Sl. No. & Journal Title & TP & Percentage & TC & ACP & H-Index \\
\hline 1 & Current Science & 683 & 8.57 & 5855 & 8.57 & 36 \\
\hline 2 & Physical Review B & 468 & 26.75 & 12521 & 26.75 & 57 \\
\hline 3 & Journal of Chemical Physics & 309 & 16.67 & 5152 & 16.67 & 35 \\
\hline 4 & Journal of Applied Physics & 297 & 14.57 & 4326 & 14.56 & 33 \\
\hline 5 & Lecture Notes In Computer Science & 279 & 2.51 & 699 & 2.50 & 11 \\
\hline 6 & Journal of Physical Chemistry B & 244 & 34.76 & 8481 & 34.75 & 48 \\
\hline 7 & AIP Conference Proceedings & 236 & 0.64 & 151 & 0.63 & 5 \\
\hline 8 & Journal Of High Energy Physics & 234 & 12.32 & 2883 & 12.32 & 29 \\
\hline 9 & Applied Physics Letters & 232 & 16.26 & 3773 & 16.26 & 33 \\
\hline 10 & Physical Review Letters & 231 & 41.64 & 9619 & 41.64 & 55 \\
\hline
\end{tabular}

Source: Web of Science February 2020

\subsection{Prolific authors wise distributions of publications}

In this analytical period, authors were published 32191 paper contributions scattered over 500 premier journals. The first 10 of authors are identified highest contributors of research at Indian Institute Science, Bengaluru. The table 6 depicts the authors wise distributions of publications published in the journal during 1999 to 2020 from Indian Institute of Science scientists/authors. In the bellow table shown the total global citation score and h-index. Kumar A is author who published 701 papers with 9451 Total Global Citation Scores with first place and in the below table- 6 shows only 
top 10 authors with citation and h-index. Kumar S with 573 papers with 8828 TGCS articles come second place and followed by other scientists/authors.

Table 6 Authors wise distributions of Publications

\begin{tabular}{|l|l|l|l|l|l|l|}
\hline Sl. No. & Authors & TP & Percentage & TC & ACP & h-index \\
\hline 1 & Kumar A & 701 & 13.48 & 9451 & 13.48 & 40 \\
\hline 2 & Kumar S & 573 & 15.41 & 8828 & 15.40 & 42 \\
\hline 3 & Bhattacharya S & 536 & 18.46 & 9895 & 18.46 & 56 \\
\hline 4 & Madras G & 499 & 25.77 & 13119 & 26.29 & 51 \\
\hline 5 & Ghosh S & 470 & 14.63 & 6874 & 14.62 & 42 \\
\hline 6 & Das S & 450 & 9.0 & 4051 & 9.0 & 31 \\
\hline 7 & Mukherjee S & 434 & 11.69 & 5072 & 11.6 & 39 \\
\hline 8 & Kumar R & 406 & 14.27 & 5794 & 14.27 & 29 \\
\hline 9 & Sharma V & 372 & 5.11 & 1900 & 5.10 & 19 \\
\hline 10 & Sarkar S & 364 & 12.57 & 4576 & 15.57 & 26 \\
\hline
\end{tabular}

Source: Web of Science February 2020

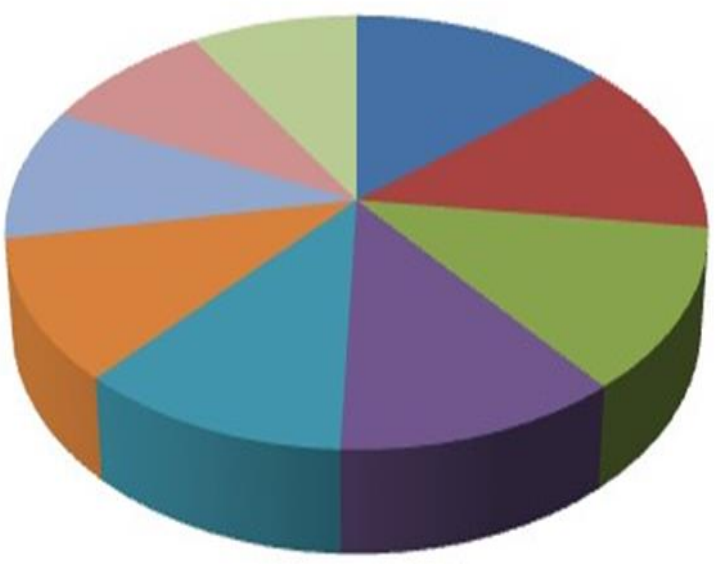

m Kumar S
m BhattacharyaS
m Madras G
m GhoshS
m DasS
m MukherjeeS
m Kumar R
mSharmaV
mSarkarS
-

Figure 6 Shows prolific author wise publications Kumar A are top rank with 701 (13.48\%) and Sarkar S is lowest rank with $364(12.57 \%)$.

\subsection{Citation Map of Highly Cited Authors}

A Citation Map shows that the citation relationships between a paper and other papers using various visualization tools and techniques. Citation mapping analysis can be applied as subject similarity indicators. It is defined as "the frequencies with two documents are cited together". (Source: Web of Science Database) 
Table 7 Top 10 Highly Cited Papers from IISC, Bengaluru, India.

\begin{tabular}{|c|c|c|c|c|c|}
\hline $\begin{array}{l}\text { Sl. } \\
\text { No. }\end{array}$ & Citations & Title & Authors & Source & Year \\
\hline 1 & 5519 & Data clustering: A review & Jain, AK; Murty, MN; Flynn, PJ & $\begin{array}{l}\text { Acm Computing } \\
\text { Surveys }\end{array}$ & 1999 \\
\hline 2 & 2568 & $\begin{array}{l}\text { Graphene: The New Two- } \\
\text { Dimensional Nanomaterial }\end{array}$ & $\begin{array}{l}\text { Rao, C. } \quad \text { N. } \quad \text { R.; Sood, A. } \\
\text { K.; Subrahmanyam, K. S.; et al. }\end{array}$ & $\begin{array}{l}\text { Angewandte } \\
\text { Chemie- } \\
\text { International } \\
\text { Edition }\end{array}$ & 2009 \\
\hline 3 & 2318 & $\begin{array}{l}\text { A dipole mode in the tropical } \\
\text { Indian Ocean }\end{array}$ & $\begin{array}{l}\text { Saji, } \quad \text { NH; Goswami, } \\
\text { BN; Vinayachandran, PN; et al. }\end{array}$ & Nature & 1999 \\
\hline 4 & 2089 & $\begin{array}{l}\text { Monitoring dopants by } \\
\text { Raman scattering in an } \\
\text { electrochemically top-gated } \\
\text { graphene transistor }\end{array}$ & $\begin{array}{l}\text { Das, A.; Pisana, S.; Chakraborty, } \\
\text { B.; et al. }\end{array}$ & $\begin{array}{l}\text { Nature } \\
\text { Nanotechnology }\end{array}$ & 2008 \\
\hline 5 & 1890 & $\begin{array}{l}\text { Overview } \quad \text { No.144 } \\
\begin{array}{l}\text { Mechanical behavior } \\
\text { amorphous alloys }\end{array}\end{array}$ & $\begin{array}{l}\text { Schuh, Christopher A.; Hufnagel, } \\
\text { Todd C.; Ramamurty, Upadrasta }\end{array}$ & Acta Materialia & 2007 \\
\hline 6 & 1713 & $\begin{array}{l}\text { Recent Advances and } \\
\text { Industrial Applications of } \\
\text { Multilevel Converters }\end{array}$ & $\begin{array}{l}\text { Kouro, } \quad \text { Samir; Malinowski, } \\
\text { Mariusz; Gopakumar, K.; et al. }\end{array}$ & $\begin{array}{l}\text { IEEE } \\
\text { Transactions On } \\
\text { Industrial } \\
\text { Electronics }\end{array}$ & 2010 \\
\hline 7 & 1712 & $\begin{array}{l}\text { Guidelines for the use and } \\
\text { interpretation of assays for } \\
\text { monitoring autophagy (3rd } \\
\text { edition) }\end{array}$ & $\begin{array}{l}\text { Klionsky, } \\
\text { J.; Abdelmohsen, } \\
\text { Akihisa; et al. }\end{array}$ & Autophagy & 2016 \\
\hline 8 & 1471 & $\begin{array}{l}\text { Supramolecular } \\
\text { Coordination: Self-Assembly } \\
\text { of Finite Two- and Three- } \\
\text { Dimensional Ensembles }\end{array}$ & $\begin{array}{l}\text { Chakrabarty, } \\
\text { Rajesh; Mukherjee, } \\
\text { Sarathi; Stang, Peter J. }\end{array} \quad$ Partha & $\begin{array}{l}\text { Chemical } \\
\text { Reviews }\end{array}$ & 2011 \\
\hline 9 & 1445 & $\begin{array}{l}\text { Supramolecular } \quad \text { gels: } \\
\text { Functions and uses }\end{array}$ & Sangeetha, NM; Maitra, U & $\begin{array}{l}\text { Chemical Society } \\
\text { Reviews }\end{array}$ & 2005 \\
\hline 10 & 1069 & $\begin{array}{l}\text { Adaptive probabilities of } \\
\text { crossover and mutation in } \\
\text { genetic algorithms classifier } \\
\text { design }\end{array}$ & Srinivas, M; patnaik, LM & $\begin{array}{l}\text { IEEE } \\
\text { Transactions On } \\
\text { Systems Man } \\
\text { And Cybernetics }\end{array}$ & 1994 \\
\hline
\end{tabular}

\subsubsection{Citation Map of Rao, C.N.R.}

Out of the total 32191 numbers of publications, author Rao, CNR is Global Citation Scores 2568 and single paper received 261 citations. The ACPP of Rao, CNR 48.49. The h-index is 57 and below figure 6 shows the citation map. 


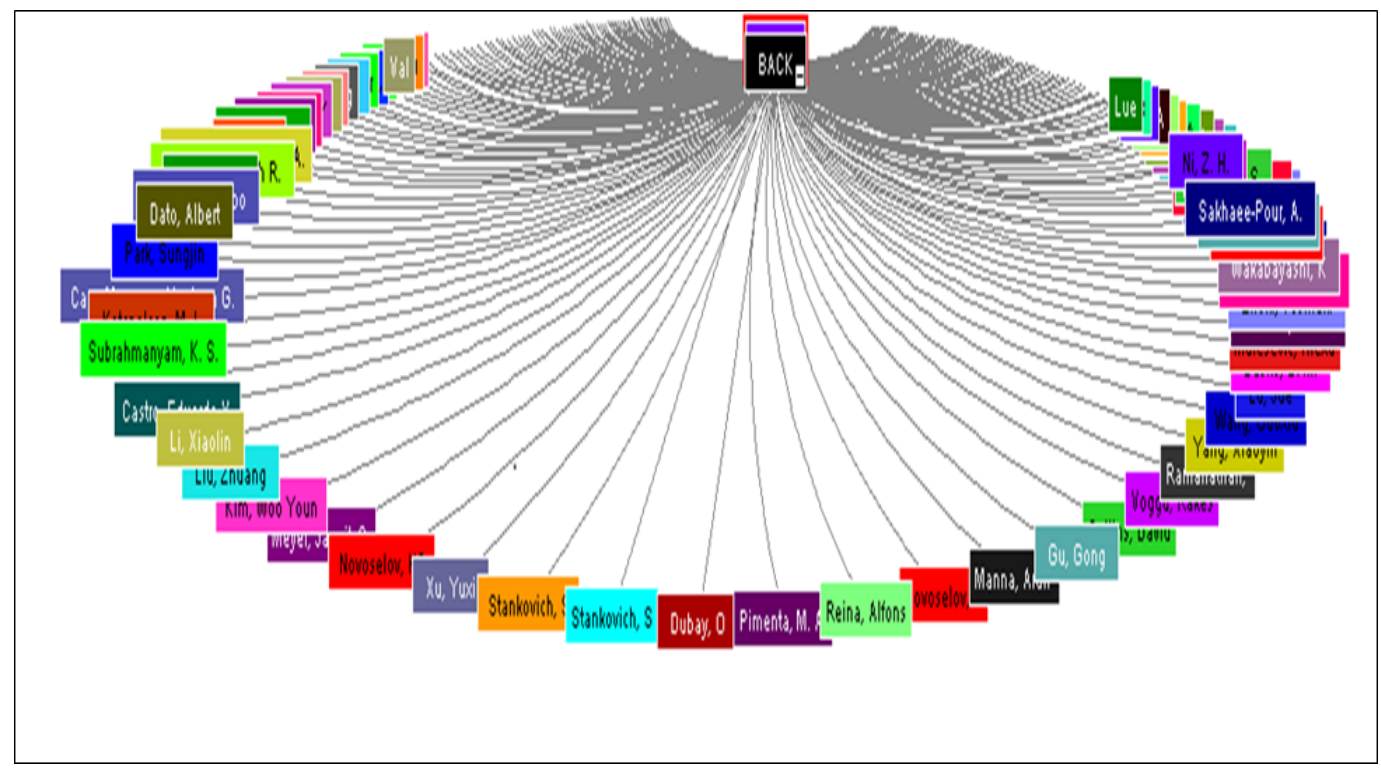

Figure 7 Shows bibliographic details: Title: Graphene: The New Two-Dimensional Nanomaterial, Author(s): Rao CNR, Sood A, Subrahmanyam K, Govindaraj, A., Source: Angewandte Chemie-International Edition, Volume: 48 Issue: 42 ,

Pages: 7752-7777, DOI: 10.1002/anie.200901678, Published: 2009, Times Cited: 1403.

\subsubsection{Citation Map of Schuh, Christopher A.}

Out of the total 32191 numbers of publications, author Schuh, CA is Global Citation Scores 1890 and single paper received 13 citations. The ACPP of Schuh, CA 21.54. The h-index is 9 and below figure 8 shows the citation map.

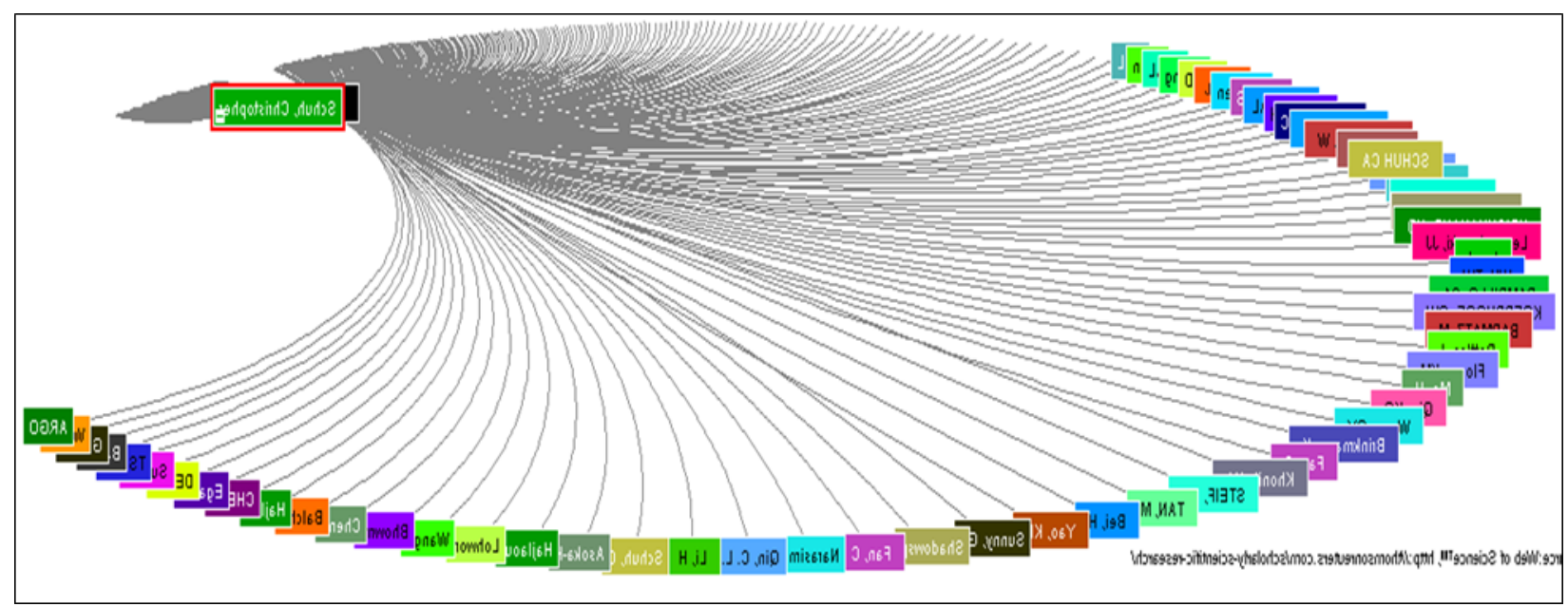

Figure 9 Shows bibliographic details: Title: Overview No.144 - Mechanical behaviour of amorphous alloys, Author(s): Schuh C, Hufnagel T, Ramamurty U., Source: ACTA MATERIALIA, Volume: 55, Issue: 12, Pages: 4067-4109, D0I: 10.1016/j.actamat.2007.01.052 Published: JUL 2007, Times Cited: 988.

\subsubsection{Citation Map of Sangeetha, N. M.}

Out of the total 32191 numbers of publications, author Sangeetha, NM is Global citation Scores 1445 and single paper received 6 citations. The ACPP of Sangeetha, NM 35.67. The h-index is 3 and below figure 9 shows the citation map. 


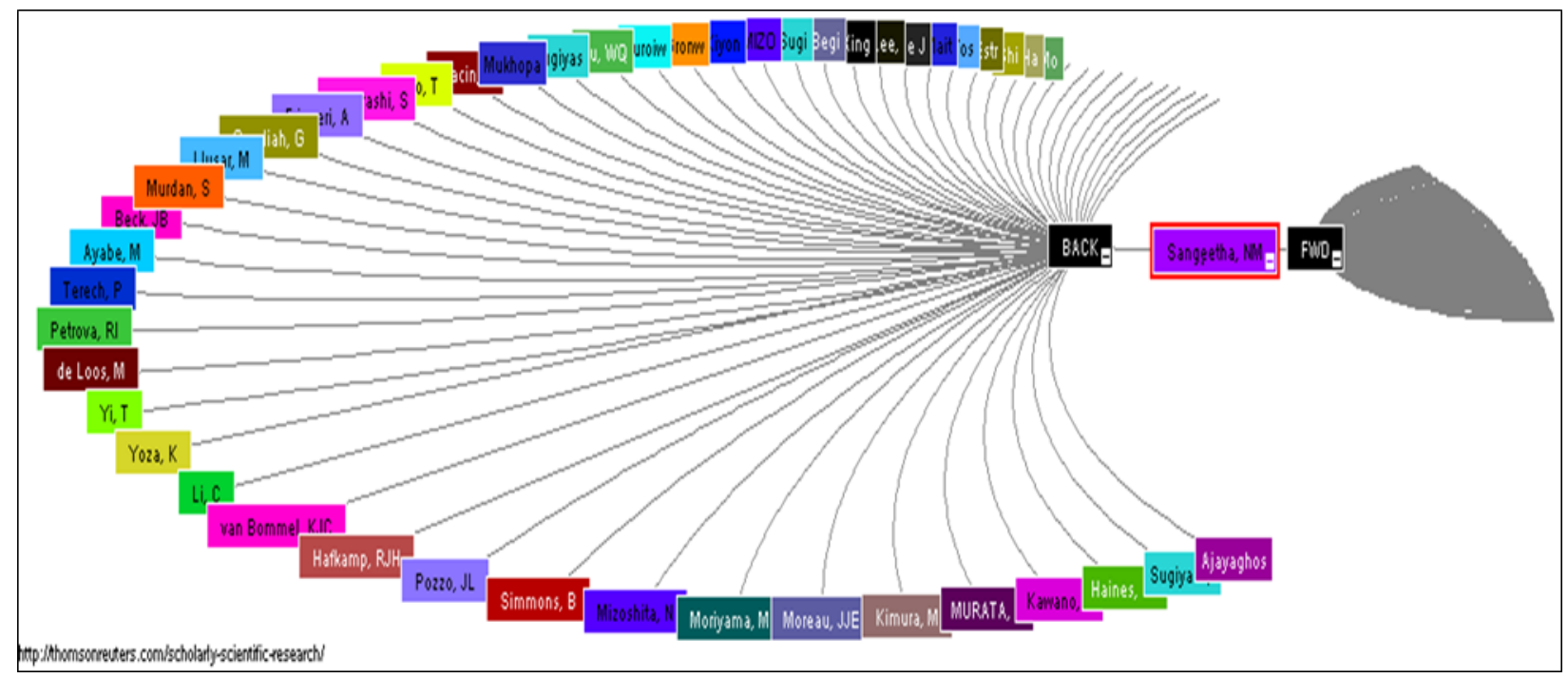

Figure 10 Shows bibliographic details: Title: Supramolecular gels: Functions and uses, Author(s): Sangeetha N, Maitra U, Source: CHEMICAL SOCIETY REVIEWS, Volume: 34, Issue: 10, Pages: 821-836, DOI: 10.1039/b417081b, published: 2005, Times Cited: 911.

\section{Conclusion}

In my research study discloses the following findings. Total number of publications is 32191 and 519184 times cited by others scientist/authors, its average citation value is 365.57. The overall year's $\mathrm{h}$ - index value is 57.36. Document wise distributions of publications for the article is top ranked with 25666 (77.15\%) and News Item last ranked with 31 (0.09\%). Subject wise distributions for the Materials Science Multidisciplinary subject is top ranked with 5051 (21.03\%) Publications and Telecommunications subject is last rank with 1271 (4.64\%). Country-wise distribution of articles published in the journal India is top ranked with 32032 (NA \%) publications and Australia is last rank with 453 (18.22\%). Journal/source wise publications published in the journal Current Science is number one ranked with 683 (8.57\%) and Physical Review Letters is last rank with 231 (41.64\%). Prolific author wise publications Kumar A are top rank with $701(13.48 \%)$ and Sarkar S is lowest rank with 364 (12.57\%). The group of citing papers includes a large number of highly cited papers we would describe as citation classics. The highest publication is 2239 in 2014 and next level by 2160 papers in 2015 and 2086 papers in 2016. The few publication 162 from 2020 year. This research paper results shows that there is considerable growth in the research output of the journal during 1999-2020 in Indian Institute of Science researchers. Overall, at the global level single author publications should be encouraged. Citation Map help the researcher and scientist to know the growth, development and research impact of particular field of research to know citation, h-index and number of publications.

\section{Compliance with ethical standards}

\section{Acknowledgments}

This paper would not be complete without acknowledging the Thomson Reuters Web of Science database. Of course the paper collected 22 years data has been collected form Web of Science database due to this the paper accomplishment successfully. As I knew without data it is not possible to complete the objectives of these study in this paper.

I also takes this opportunity to thanks all authors in the references I has been mentioned in the bellow. Who are published in the previous years, I have been referred their published article and got clear idea to write this paper successfully.

\section{Disclosure of conflict of interest}

As the paper is authored by single author so there is no conflict of interest. 


\section{References}

[1] Jayashree B, Arunachalam S. Mapping fish research in India. Current Science. 2000; 79(5): 13-620.

[2] Madhan M, Chandrasekhar G, Arunachalam S. Highly cited papers from India and China. Current Science, 2010; 99(6): 738-749.

[3] Rajagopal T, Archunan G, Surulinathi M, Ponmanickam P. Research output in pheromone biology: A case study of India. Scientometrics. 2012; 1-9.

[4] Ankasetty K, Surulinathi M. Highly Cited Papers from University of Mysore: A Citation Mapping. Journal of Advances in Library and Information Science. 2013; 2(2): 50-54.

[5] Thomson Reuters Web of Science.

[6] Nagarjuna, Pitty, Shambhulinga Irappa Javali. Highly Cited Paper from Indian Indian Institute of Science, Bangalore, India during 2001-2014 `: A Scientometrics Analysis Case Study, CALIBER 2015, and ISBN 978-9381232-05-7. 2015; 107-117. 